Topic familiarity, passage sight vocabulary, and L2 lexical inferencing: An investigation in the Iranian EFL context

\author{
Atef-Vahid, Sara $\bowtie$ \\ Iran University of Science and Technology, Iran (saraatefvahid@yahoo.com) \\ Maftoon, Parviz \\ Islamic Azad University, Iran (pmaftoon@srbiau.ac.ir.ac.ir) \\ Zahedi, Keivan \\ Shahid Beheshti University, Iran (kzahedi@sbu.ac.ir)
}

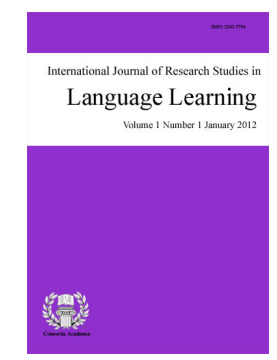

ISSN: 2243-7754 Online ISSN: 2243-7762

OPEN ACCESS

\title{
Abstract
}

This study investigates the effects of topic familiarity and passage sight vocabulary on L2 lexical inferencing in the EFL (English as a foreign language) learning context of Iran. 114 undergraduate university students read four narratives (2 more and 2 less familiar) constructed by Pulido (2000) containing 32 nonsense words. The meanings of the target words were inferred and difficulty in guessing was rated. Analyses of the repeated-measures design reveal (1) a strong impact of topic familiarity and an independent effect of passage sight vocabulary on L2 lexical inferencing, (2) significant impact of passage sight vocabulary and no significant effect of topic familiarity on the perceived difficulty/ease in L2 lexical inferencing, and (3) no significant interaction between topic familiarity and passage sight vocabulary on L2 lexical inferencing and difficulty/ease in L2 lexical inferencing. The significance of the findings pertaining to lexical inferencing is discussed, and practical pedagogical implications and applications are presented.

Keywords: topic familiarity; passage sight vocabulary; L2 lexical inferencing; difficulty/ease in L2 lexical inferencing; EFL 


\section{Topic familiarity, passage sight vocabulary, and L2 lexical inferencing: An investigation in the Iranian EFL context}

\section{Introduction}

In the course of acquiring a new language system, incoming input must be decoded in some comprehensible mode for comprehension to occur. In the case of L2 reading comprehension, the reader uses various available resources such as previous knowledge to construct and integrate meaning from the text (see, e.g., Koda, 2007; Nassaji, 2002). Results from previous research have shown consistently high correlations between vocabulary knowledge and reading comprehension (e.g., Davis, 1968; vanDaalen-Kapteijns \& Elshout-Mohr, 1981) which suggests "successful comprehension is strongly related to knowledge of individual word meanings" (Koda, 2007, p. 5). For example, vocabulary size has been shown to be a strong indicator of reading success (e.g., Haynes \& Baker, 1993). Consequently, Laufer (1997) concluded that for L2 readers the "threshold for reading comprehension is, to a large extent, lexical" (p. 21). That is, a threshold vocabulary level is assumed to be required for the successful transfer of L1 metacognitive reading strategies to L2 reading tasks.

Most research studies agree that vocabulary is, if not the best, a good predictor of reading (Laufer, 1992; Nation, 2006). However, not much consensus exists on the relative amount of vocabulary which is required for successful comprehension. Laufer (1989) suggested 95\% coverage, and Laufer (1992) suggested knowing 3,000 word families to provide the lexical supply while independently reading authentic materials. However, more recently, Laufer and Ravenhorst-Kalovski (2010) suggest two thresholds consisting of an optimal one (knowledge of 8,000 word families giving way to $98 \%$ coverage), and a minimal one (4,000-5000 word families resulting in the coverage of $95 \%$.) Furthermore, they emphasize that lexical text coverage--the percent of words that a reader understands--and the readers' sight vocabulary size- words whose meanings are recognized automatically regardless of context- are two related factors of lexical threshold. They argue that the larger the sight vocabulary, the greater the text coverage. Other studies suggest having knowledge of 98-99\% of the text words for adequate comprehension (Hu \& Nation, 2000). Similarly, Nation (2006) used this updated percentage $(98 \%)$ and concluded that knowledge of $8000-9000$ word families is indeed necessary for reading comprehension. Interestingly enough, in a more recent study, Schmitt, Jiang, and Grabe (2011) actually argue against any threshold level for vocabulary knowledge. They found no apparent point at which comprehension noticeably increased, rather observed a consistent linear relationship between increasing vocabulary knowledge and reading comprehension.

During the course of reading, however, readers may encounter unknown words. Therefore, in an attempt to achieve overall comprehension, the reader may try to derive word meanings from context. This first requires forming rough plausible hypothesis of probable word meanings from initial encounters. This can be done using information contained within the text and learner knowledge sources (e.g., background knowledge and passage-specific sight vocabulary), because these factors can influence processing and help determine the availability of textual clues for inferencing. Then, subsequent textual pieces of information must be taken into account and be integrated with previous information. Finally, initial hypothesis must be restructured and modified according to all acquired information. Therefore, in the process of reading, it is assumed that learner knowledge sources interact with text features-yielding a variety of factors that can, independently or conjointly, influence inferencing and possibly the learning of unfamiliar words from context (Huckin \& Coady, 1999; Hulstijn, Hollander, \& Greidanus, 1996; Paribakht \& Wesche, 1999).

Currently, a prominent issue in second language acquisition (SLA) research concerns the nature of the conditions and processes underlying L2 lexical competence and development, as well as the impact and interaction between such reader-based factors as background knowledge/ topic familiarity (TF), and passage-specific vocabulary knowledge or passage sight vocabulary (PSV) in L2 lexical inferencing (L2 LI) 
Topic familiarity, passage sight vocabulary, and L2 lexical inferencing

(Pulido, 2007). This study aimed at investigating in a controlled fashion the impact and interaction between the aforementioned variables in an Iranian EFL learning context, when a cross-section of Iranian EFL learners were assigned a strategic task involving L2 LI and the processing of new vocabulary in narratives. A study of this nature may be able to increase our understanding of individual differences and variability found in L2 and consequently further expand our knowledge about the nature and impact of reader-based variables such as PSV and TF on this process. Pedagogical implications may be warranted, as detailed insight into the nature and impact between such reader-based variables may be able to assist foreign language educators in determining the appropriateness of language learning tasks and texts used for vocabulary growth and development.

\section{Literature review}

\subsection{Effects of Background Knowledge on Lexical Inferencing}

In the task of reading, relevant knowledge that the reader possesses can determine the extent to which a text can be understood (Spilich, Vesonder, Chiesi, \& Voss, 1979). Various research studies have shown the contributions of higher levels of background knowledge to efficiency of attentional allocation to input during reading (e.g., Graesser, Singer, \& Trabasso, 1994; Kintsch 1988; Nassaji 2002). Higher levels of background knowledge can provide richer textual interpretations which can result in better remembering what has been read, and consequently, in advanced memory performance. Diakidoy (1998) proposed that pertinent knowledge in a field means that at least some of the significant concepts of the field are known (enabling concepts). The ways in which these enabling concepts are or can be related are known to some extent, and they are thought to facilitate the learning of unknown concepts. Considering enabling concept knowledge and general topic knowledge, it can be assumed that a rich knowledge base can help generate and impel initial hypotheses about any unfamiliar words by providing the reader with the position and function of the concept underlying the word in a network (Diakidoy, 1998, p. 135). Furthermore, the same knowledge can assist inferencing when necessary information or relations are missing. As Grabe (2004) asserts, background knowledge paves the way for disambiguating lexical meanings and syntactic ambiguities, and is therefore necessary for all types of inferencing and text model construction.

Research surrounding the LI paradigm, however, has provided mixed results on the role of background knowledge on learners' inferencing abilities. These studies attempted to investigate the strategies and knowledge sources used by L2 learners during the LI process. Numerous studies have shown that regardless of the participants L1 language backgrounds or language proficiency levels, background knowledge was used in the task of inferring the meanings of unknown words while reading expository texts (e.g., Chern, 1993; de Bot, Paribakht, \& Wesche, 1997; Haastrup, 1989; Nassaji, 2003; Paribakht \& Wesche, 1999; Parry, 1997). In a study by Pulido (2002, cited in Pulido, 2004), similar positive results on the effects of background knowledge on LI were obtained while L2 learners read narrative texts. In Adams's (1982) study, it was shown that when L2 learners were aware of the topic, they were more successful in LI. Similarly, Pulido (2007) found that TF had a significant impact on LI because target word inferencing increased when a more familiar scenario was read compared to a less familiar scenario. However, several studies have reported that the proficiency levels of L2 learners affected their use of background knowledge. For example, Lee and Wolf (1997) found that background knowledge was used the most by native Spanish speakers, then by the advanced, intermediate, and beginning learners. Parry's (1997) study illustrates how the selection of words to be inferred in advanced EFL learners' anthropology texts was based on their anthropology knowledge.

Few studies had shown that when L2 learners encounter unfamiliar words in expositions, they either did not appeal frequently to background knowledge or inappropriately applied it during inferencing (e.g., Haynes \& Baker, 1993). Rott (2000, cited in Pulido, 2007) observed that during inferencing, background knowledge was only used by a small number of intermediate learners of German. Several studies have also shown the preference of intermediate ESL learners to appeal to grammatical knowledge rather than to background knowledge (e.g., de 
Atef-Vahid, S., Maftoon, P., \& Zahedi, K.

Bot et al., 1997; Paribakht \& Wesche, 1999).

\subsection{Effects of Passage Sight Vocabulary on Lexical Inferencing}

Aside from the use of domain knowledge, there exist other determinants of reading success and acquiring information from texts, such as efficient strategy use, decoding ability, and language skills. In this regard, Stanovich (1986) argues that the key mechanism allowing for capacity to be allocated to comprehension during reading is efficient decoding and word recognition skills. The significance of general vocabulary knowledge and word recognition efficiency in reading success has been pointed out in various L2 reading research (e.g., Koda, 2007; Mecartty, 2000).

Meaning construction during reading, which is a complex cognitive skill, requires the use of an important type of linguistic knowledge which is related to the vocabulary associated with the text referred to as passage sight vocabulary (PSV) (Pulido, 2003, 2004). PSV is defined as the knowledge of the forms and common meanings of vocabulary which are specifically related to the text at hand, and which are recognized automatically, irrespective of context (Pulido, 2000, 2007; Pulido \& Hambrick, 2008).

Allocating attentional resources during text comprehension processes (e.g., parsing sentences, construction and integration of ideas from context, monitoring comprehension, accessing and using information from long-term memory) requires possessing processing skills such as efficient decoding skills, adept word recognition skills, such as adequate PSV (Pulido, 2007; Pulido \& Hambrick, 2008). PSV can contribute to an array of processes which occur during reading (e.g., input processing, comprehension, vocabulary acquisition, etc.), and therefore increase the overall chance of successful LI which can ultimately facilitate lexical growth and development (Pulido, 2004; Pulido \& Hambrick, 2008). As Ellis (1995) stresses, one of the primary processes involved in vocabulary acquisition through reading is LI, and without the aforementioned processing skills, there is a greater chance that readers will not be able to relate information and ideas in the text which is essential in LI and new meaning integration, and as a result, fewer chances for vocabulary development (Koda, 2007; Laufer, 1997).

Regarding vocabulary breath and vocabulary development through reading, research has underscored the importance of sufficient PSV in not only enhancing comprehension, but also in promoting contextual inferencing of unfamiliar words (e.g., Daneman \& Green, 1986; Haynes, 1993; Haynes \& Baker, 1993; Hirsh \& Nation, 1992; Horst et al., 1998; Huckin \& Coady, 1999; Laufer, 1997). Numerous studies have reported successful LI when readers knew more vocabulary in the passage (e.g., Haynes, 1993; Haynes \& Baker 1993; Parry 1997). A few studies had also measured the amount of known vocabulary in a target passage before it was read in an attempt to discover the role of this knowledge on new vocabulary gains (e.g., Pulido, 2002, cited in Pulido, 2004; 2003). From the results of these studies, it was concluded that LI ability can be strongly predicted and determined by PSV. In a different cross-sectional study, Pulido (2007) found significant effects of PSV on measures of LI, difficulty/ease in LI, and receptive retention of target word meanings. The results of this study showed that learners with greater levels of PSV reported greater ease in inferring the target words from the more familiar passage.

The combined findings from previous research indicate that during the complex task of reading, learners must activate all types of available knowledge and resources at their disposal. Such learner factors as TF and PSV which are assumed to vary from individual to individual come into play to affect text processing and assist lexical input processing and inferencing.

\section{Research questions}

To fulfill the purposes of this study, the following research questions were raised:

A. Does topic familiarity have any statistically significant impact on the L2 lexical inferencing of Iranian 
university students when reading narratives?

B. Does passage sight vocabulary have any statistically significant impact on the L2 lexical inferencing of Iranian university students when reading narratives?

C. Does topic familiarity have any statistically significant impact on the difficulty/ease in L2 lexical inferencing of Iranian university students when reading narratives?

D. Does passage sight vocabulary have any statistically significant impact on the difficulty/ease in L2 lexical inferencing of Iranian university students when reading narratives?

For statistical convenience, null hypotheses for all research questions were assumed.

\section{Method}

\subsection{Participants}

The participants targeted in this study were 114 Iranian undergraduate students enrolled in the spring semester in computer engineering, physics, chemistry, and mathematics B.S. programs at the University of Shahid Beheshti, Tehran, Iran. The participants were all taking the same General English course and were at the intermediate level (or above) of English proficiency as screened by a PET test. All participants were native speakers of Persian.

\subsection{Instrumentation}

$>$ Preliminary English Test (PET): A Preliminary English Test was used to isolate students at the intermediate (or higher) level of English proficiency and therefore assure their homogeneity in terms of English language proficiency. Accordingly, a PET was administered to 276 undergraduate students of which a total of 114 students where ultimately chosen.

$>\quad$ Participant Questionnaire: A Participant Questionnaire tapping background knowledge was employed to determine which topics were more and less familiar to the participants. This questionnaire collected information in four different areas in an attempt to avoid causing awareness of the aim of the research as to prevent bias : (A) background information about the students, (B) a self-reported assessment about English language learning motivation, (C) themes (to assess TF), and (D) a self-reported questionnaire concerning cognitive strategy use to tackle various classroom tasks. Part $\mathrm{C}$ was in the form of a 10-item Likert scale which indicated the degree of information that participants had on a certain topic, on a scale of 1 (No Information) to 5 (Complete Information).

$>$ Passage Sight Vocabulary Measure: A PSV Measure in the form of a vocabulary checklist and translation (L2 to L1, i.e., English to Persian) was utilized in order to obtain for each participant a baseline measure of their passage-specific sight vocabulary. This was a supply-definition/L1 translation measure which consisted of an English to Persian (L2 to L1) translation option for each item assessing receptive vocabulary knowledge.

$>\quad$ Reading Passages: The reading passages used in this study were four narratives; two pertaining to more familiar and two to less familiar scenarios, based on the results obtained from the Participant Questionnaire. Each passage contained eight nonsense words to determine successful inferencing of the target words. All of the scenarios represented everyday routines or scenarios based upon personal experience, which were constructed by Pulido (2000).

$>\quad$ Target Words: Thirty-two lexical items were chosen evenly from the four narratives (eight words per passage) which represented concepts most frequently associated with the scenarios. These lexical 
items were chosen because they represented enabling concepts (Diadikoy, 1998, p.135). The thirty-two lexical items were then substituted with nonsense words, which served as the target words under investigation. The nonsense words were invented words that were constructed according to the orthographic and morphemic rules of English. All derivational and inflectional morphemes were also maintained. Each passage yielded a minimum of one or a maximum of three verbs, and a minimum of five, and a maximum of seven nouns.

> Difficulty/Ease in L2 LI Questionnaire: The level of difficulty/ease in L2 lexical inferencing was determined by responses on a Likert-scale questionnaire tapping level of difficulty/ease in inferring the meaning of each target word (Appendix A). The following scale was used: $1=$ very difficult, $2=$ difficult, $3=$ =moderately difficult, $4=$ =moderately easy, 5=easy, $6=$ =very easy.

\subsection{Procedure}

This research was carried out in three separate phases. In Phase One, the PET was piloted on 30 undergraduate students studying at the Engineering School of Shahid Beheshti University which were taking the same General English course as the target participants.

In Phase Two, the PET and the Participant Questionnaire were administered to the target students. The results indicated that, overall the The Trip to the Supermarket and The Doctor's Appointment, were more familiar than the Publishing an Article and Buying a Home narratives.

Since the obtained results were the same as Pulido's (2000) study (regarding the familiarity of the passages), therefore, the same narratives were used. However, to ensure that the four narratives were suitable for participants at the intermediate level of English language proficiency, Flesch Reading Ease measure was used to compare the readability of the narratives with narratives from the PET administered at the beginning of the study. The four narratives had very close readability values and were assumed to be at the same level of difficulty. Their average readability was $M=74.03$, and the mean of the readability of the narratives from the PET was $M=$ 73. Because of the closeness of the readability scores, it was assumed that the passages where at the same level of difficulty, therefore, reflecting an intermediate level of English proficiency.

In Phase Three, the PSV Measure was administrated. Since all four narratives contained, on average, between 182-189 words each, it was not feasible to test the translation of every single vocabulary item comprising each of the four texts. Therefore, the number of words in each passage was estimated, and from this figure, those words students at the level of intermediate or over would likely know from the four narratives were deleted. They included pronouns, proper names, quantifiers and qualifiers, sequence markers, and function words (e.g., prepositions, articles, WH words, as well as subordinating and coordinating conjunctions), approximately $30 \%$ of the words in each story. After the target words were also put aside, the remaining words were put into alphabetical order, and then randomized using prime numbers, which yielded a total of 93 words to be tested. Ultimately, the remaining percentage of passage-specific words selected from each passage and included into the PSV measure was as follows: (a) The Trip to the Supermarket - 34.72\%; (b) The Doctor's Appointment - 51.61\%; (c) Publishing an Article - 42.18\%; and (d) Buying a Home- 35.82\%. During this phase, the directions were read out loud, and a model was demonstrated by the researchers. Then the participants were instructed to indicate either a yes or a no specifying as to whether or not they were familiar with the L2 vocabulary item. Finally, they were instructed to translate or define those words which were familiar to them in Persian (L1), and to leave blank those unfamiliar ones. Since the sole purpose of this measure was to identify those passage-specific (nontarget) words that were previously known and could be immediately recognized by the participants, irrespective of context, they were instructed not to guess, but to translate or define only familiar words. The order of the presentation of the tests was counterbalanced across the participants to ensure that all vocabulary item test sheets had the opportunity to be encountered with similar frequency in similar ordering patterns. 
Topic familiarity, passage sight vocabulary, and L2 lexical inferencing

It should be noted that some words included in the PSV measure were repeated throughout the narratives. Therefore, in the calculation process, this was taken into account and points were fixed for each passage. As a result, the maximum obtainable score for the PSV measure was 108 for all passages combined. Scores were based on measuring the partial-precise knowledge of the words. If participants knew the precise passage meaning of the word or a polyseme either representing the meaning of the word corresponding to the passage or a non-passage meaning received one point. The participants were given partial credit (0.5 points) if they demonstrated partial knowledge of the word. This would be the case if the translation of the target word was close or relevant to its actual meaning (e.g., if the word neighborhood was translated as neighbor). Zero points were allotted if a 'no' response was given-rating an item as unfamiliar-, or a 'yes' response was given-rating an item as familiar- but an accurate definition of the meaning of a word was not provided.

To conclude, the results of the PSV measure served as a covariate, and were used not only to investigate the impact of L2 passage-specific sight vocabulary on L2 LI through reading, but also to adjust for potential preexisting differences among the participants associated with the covariate of PSV.

Next, the L2 LI Measure was administrated. Instructions were given to promote careful attention while reading each passage, focusing on the title which served as the 'script instantiator' for relevant prior knowledge. Since participants read all four passages, their order of presentation was counterbalanced. This was to avoid test effects that might occur as the participants gain practice with the repeated reading sequence. It was explained to the participants that they would be reading each of the four narratives at least twice at their own pace for comprehension. Then, after reading each passage, they would have to provide L1 translations or explanations of the meaning of the target bold-faced underlined words in each passage in the space provided. The L2-L1 translations or definitions were assessed along a partial-precise dimension according to how well the students could translate or define the target words.

Last, the measure tapping perceived difficulty/ease in L2 LI was distributed to the participants. Immediately after each target bold-faced underlined word was inferred in each passage, the participants were instructed to rate on the following page the level of difficulty/ease in inferring that particular word. Each participant's rating average was tabulated, and ultimately the total mean scores of all participants' ratings was combined, calculated and utilized for statistical analyses.

\section{Results}

The collected data comprised an approximate figure of 19,000 items to be analyzed. To this end, the General Linear Model statistics tool, incorporating the Repeated Measures tool was used where TF was the within-subjects variable consisting of two levels: more and less familiar passages. PSV was the covariate, and L2 LI and level of difficulty/ease in L2 LI were the dependent variables. Paired t-tests, and Pearson Moments Correlations where appropriate, were used to delineate more precise analytical figures and measures.

The results indicated that the PSV scores had considerable variation across the participants (combined average of all passages $M=99.17, S D=9.38$; more familiar passages $M=53.04, S D=5.55$; less familiar passages $M=45.80, S D=5.13$ ). The participants were successful in providing the translation of $91.82 \%$ of the vocabularies presented in the test. Furthermore, a paired t-test confirmed that better performance was demonstrated for the more familiar passages $(t(113)=36.17, p=.0001<.05)$. Regarding L2 LI, combined scores revealed that more than half (about 60.69\%) of the target words from all passages combined were successfully inferred by the participants $(M=19.42, S D=5.13)$. Furthermore, target words were inferred more in the more familiar passages (more familiar $M=11.25, S D=2.85$; less familiar $M=8.17, S D=2.83$ ).

There were positive moderate Pearson Correlations between the scores of the PSV and the L2 LI scores of all passages combined $(r=.456, p=.001<.01)$. That is, as PSV increases, so does the number of target words correctly inferred. The correlation was slightly higher for the less familiar passages $(r=.47, p=.001<.01)$ compared to the more familiar ones $(r=.39, p=.001<.01)$, suggesting that where the participants did not have 
Atef-Vahid, S., Maftoon, P., \& Zahedi, K.

the appropriate background knowledge, they tended to rely more on their previously acquired vocabulary knowledge.

The results from the repeated measures (Table 1 below) revealed a consistent significant main effect for the within subject variable of $\operatorname{TF}\left(F(1,112)=5.34, p=.023<0.05, \eta^{2}=.046\right)$, and the covariate of PSV $(F(1,112)$ $\left.=29.40, p=.001<.05, \eta^{2}=.208\right)$ on L2 LI at the significance level of $p=.05$. This means that there is a significant difference between the means of the L2 LI scores of the more and less familiar passages, thus rejecting the first null hypothesis. Furthermore, based on the obtained value of partial eta squared, approximately $21 \%$ of the variance of the L2 LI scores is related to PSV. Therefore, based on these results, it can be concluded that the second null hypothesis can be rejected as well.

The interaction between TF and the covariate of PSV was not shown to be significant at the $p=.05$ level $(F$ $\left.(1,112)=1.11, p=.295>0.05, \eta^{2}=.01\right)$ (Table 1). Based on the results mentioned above, a significant relationship between PSV and L2 LI exists; however, only $1 \%$ of the variance of PSV is dependent on the familiarity of the passages.

\section{Table 1}

Statistical results of the effect of TF on L2 LI using PSV as the covariate variable

\begin{tabular}{|c|c|c|c|c|c|c|c|c|}
\hline Source & Topic & $\begin{array}{l}\text { Type III } \\
\text { Sum of } \\
\text { Squares }\end{array}$ & $d f$ & Mean Square & $F$ & Sig. & $\begin{array}{c}\text { Partial Eta } \\
\text { Squared } \\
\left(\eta^{2}\right)\end{array}$ & $\begin{array}{c}\text { Observed } \\
\text { Power }^{\mathrm{a}}\end{array}$ \\
\hline Topic & Linear & 15.883 & 1 & 15.883 & 5.340 & .023 & .046 & .630 \\
\hline \multirow[t]{2}{*}{ Topic * PsvTotal } & Linear & & & & & & & \\
\hline & & 3.289 & 1 & 3.289 & 1.106 & .295 & .010 & .181 \\
\hline Error(Topic) & Linear & 333.106 & 112 & 2.974 & & & & \\
\hline PsvTotal & & 308.673 & 1 & 308.673 & 29.398 & .001 & .208 & 1.000 \\
\hline Error & & 1175.972 & 112 & 10.500 & & & & \\
\hline
\end{tabular}

Note. Tests of Within-Subjects Contrasts and Between-Subjects Effects. Computed using alpha $=.05$

To address the issue of the difficulty/ease in L2 LI, descriptive statistics revealed that on average participants reported moderate difficulty in L2 LI in all passages combined $(M=3.39, S D=1.29$, scale of 1-6). However, there was slightly more variability in ratings in the more familiar passages $(M=3.93, S D=1.38)$ than in less familiar ones $(M=2.85, S D=1.16)$. It seems that the target words from the more familiar passages were considered easier to infer. That is, LI of the vocabulary in the less familiar passages seemed to be perceived more difficult for the participants than those of the more familiar passages.

Pearson correlations revealed that there also existed a fairly low positive relationship between PSV scores and difficulty/ease in L2 LI scores of all passages combined $(r=.27, p=.003<.01)$. That is, perceived difficulty/ease in L2 LI was directly proportionate to PSV knowledge when all passages were combined. The repeated measures analysis did not reveal a significant effect of the variable of TF $(F(1,112)=1.95, p=.165$ $>$.05) on difficulty/ease in L2 LI (Table 2).

Although there is a difference in the mean scores of difficulty/ease in L2 LI in the more and familiar passages, the difference in means is not statistically significant. Therefore, based on these results, the third testing hypothesis stating that TF does not have a statistically significant impact on the difficulty/ease in L2 LI of university students when reading narratives cannot be rejected. However, the repeated measures analysis revealed a constant significant main effect of the covariate of PSV $\left(F(1,112)=11.13, p=.001<.05, \eta^{2}=.090\right)$ on difficulty/ease in L2 LI at the significance level of $p=.05$. Furthermore, based on the value of partial eta-squared, approximately $9 \%$ of the variance of the difficulty/ease in L2 LI scores is related to PSV. Therefore, from these results, it can be concluded that the fourth testing hypothesis can also be rejected. 
Topic familiarity, passage sight vocabulary, and L2 lexical inferencing

Table 2

Statistical results of the effect of TF on difficulty/ease in L2 LI using PSV as the covariate variable

\begin{tabular}{|c|c|c|c|c|c|c|c|c|}
\hline Source & Topic & $\begin{array}{l}\text { Type III Sum } \\
\text { of Squares }\end{array}$ & $d f$ & Mean Square & $F$ & Sig. & $\begin{array}{c}\text { Partial Eta } \\
\text { Squared } \\
\left(n^{2}\right)\end{array}$ & $\begin{array}{l}\text { Observed } \\
\text { Power }^{\mathrm{a}}\end{array}$ \\
\hline Topic & Linear & 72.554 & 1 & 72.554 & 1.951 & .165 & .017 & .283 \\
\hline Topic * PsvTotal & Linear & 5.754 & 1 & 5.754 & .155 & .695 & .001 & .068 \\
\hline Error(Topic) & Linear & 4165.075 & 112 & 37.188 & & & & \\
\hline PsvTotal & & 7488.028 & 1 & 7488.028 & 11.125 & .001 & .090 & .911 \\
\hline Error & & 75386.695 & 112 & 673.095 & & & & \\
\hline
\end{tabular}

Note. Tests of Within-Subjects Contrasts and Between-Subjects Effects. Computed using alpha = .05

From the results presented in Table 2, it can also be concluded that the interaction between TF and PSV at the significance level of $p=.05$ is not statistically significant $\left(F(1,112)=.16, p=.695>.05, \eta^{2}=.001\right)$. Based on these results, there is a significant relationship between PSV and difficulty/ease in L2 LI; however, only .1\% of the variance of PSV is dependent on the familiarity of the passages. That is, the perceived difficulty of the participants on the L2 LI measure for the more and less familiar passages was almost the same.

\section{Discussions}

To determine the impact of the two variables of TF and PSV on L2 LI and difficulty/ease in LI, the following discussion focuses first on the impact of the two variables on L2 LI, and then on difficulty/ease in L2 LI.

Based on the results obtained in this study, and consistent with Pulido's (2007) findings, it was found that TF had a statistically significant impact on L2 LI. There were considerably more correct target word inferences when reading about a more familiar scenario compared to a less familiar scenario. Reading the more familiar scenarios could have enabled the participants to create a well-formed schema to relate their prior knowledge to the situations presented in the scenarios. Evidence from previous research has shown that such background knowledge can be expected to facilitate comprehension and word learning from context (e.g., Freebody \& Anderson, 1983), and also L2 LI (e.g., Adams, 1982; Pulido, 2000, 2007).

When appropriate background knowledge is available--the result of reading a more familiar text--readers may be able to direct their attention to textbase input. Pulido (2007) argues that during reading, various local and global cues can prompt the activation of an array of the readers' knowledge (e.g., syntactic, semantic, pragmatic) which can assist in meaning construction. These knowledge sources are held in the working memory and support the processes involved in interpreting the text. Consequently, new words can be processed based on form-meaning mappings. It is very likely that the participants of the present study were facilitated to construct ideas from the context and tried to infer the meanings of unfamiliar words to achieve necessary comprehension. Therefore, the results of this study are in line with the theory that the organization of one's past experiences influences comprehension (Carrell, 1983). Furthermore, since meaning construction entails relating input information to information stored in long-term memory, when the content of the input is familiar to the reader or listener, this process is facilitated (Lesser, 2004).

As a result, the consistent superior inferencing abilities of the participants of this study when reading more familiar scenarios in comparison to less familiar scenarios can support schema theoretic views of comprehension, as well as learning and memory performance. Here, higher levels of familiarity with the familiar scenarios could have provided a cognitive foothold upon which rich representations were developed. That is, it could be argued that greater background knowledge allowed for more elaborate analyses, more efficient attentional allocation, and richer interpretations in the course of constructing meaning (Graesser et al., 1994; Lockhart \& Craik, 1990). By studying readers' cognitive processes during vocabulary meaning construction, the important role that 
background knowledge plays in facilitating this process is underscored. In sum, the results obtained from testing the first research question demonstrate a substantial impact of TF on L2 LI.

With regard to PSV, the results indicated that increase in PSV knowledge increased the ability to infer correctly the meanings of the target words. This finding highlights the strong role that PSV plays during the process of creating form-meaning connections for new words during the task of reading. The results of this study are also in line with Pulido's (2007) research where it was found that PSV has robust effects on L2 LI. The reason for this finding can be that where the amount of known vocabulary decreases so may comprehension, which, in effect, may affect the overall inferencing ability of the participants. Also, as Pulido (2007) argues, "when readers know more vocabulary in a passage they may also have more available context and clues from which to interpret specific relationships among ideas and any new vocabulary contained therein" (p.81). Furthermore, Pulido (2007) claims "since recognizing words entails accessing meaning, when lexical access is laborious and/or inaccurate, this may strain the processing resources also needed for syntactic parsing, propositional generation, retention of information in working memory, and access to information in long-term memory" (p. 81). Other previous research has also indicated high correlations between inferencing success and vocabulary knowledge (e.g., Hafner, 1967, cited in Bengeleil \& Paribakht, 2004; Herman, Anderson, Pearson, \& Nagy, 1987).

The findings of the present study also indicate that although a significant relationship between PSV and L2 LI was shown to exist, only a negligible percentage of the variance of PSV was shown to be dependent on the familiarity of the scenarios. This finding suggests that the previous acquired vocabulary knowledge of the participants assisted them in the LI process regardless of the familiarity of the scenarios. Furthermore, a slightly stronger relationship was found to exist between PSV and L2 LI in the less familiar scenarios. A possible explanation could be that where the participants did not have the appropriate background knowledge, they tended to rely more on their previously acquired vocabulary knowledge to assist them in the LI task. This may suggest that in the less familiar scenarios, the role of PSV is highlighted to some extent. This finding is contradictory to Pulido's (2007) finding, where PSV was suggested to have a stronger contribution to LI when readers possessed suitable background knowledge.

At first glance, it seemed that TF affected perceived difficulty/ease in L2 LI because target words from the more familiar scenarios were perceived to be less difficult to infer in comparison to the less familiar scenarios. However, after running thorough statistical analysis, it was established that the difference in the perception of the participants in inferring the meanings of the target words of the more and less familiar scenarios was not statistically significant. Overall, the participants expressed moderate difficulty in the L2 LI task, regardless of familiarity with the topic. This is contrary to Pulido's (2007) results where a significant effect of TF on difficulty/ease in LI was shown. The value of these differences is that it may signal an effect of different L1 and L2 populations in the two studies, which is a useful result for an applied linguistics readership.

The statistical analysis of this study further revealed a positive relationship between PSV and difficulty/ease in L2 LI. The results show that as PSV scores of the participants increased, so did their ease in inferring the meanings of the target words. This suggests that the more PSV knowledge the participants possessed, the easier L2 LI was perceived to be. Although a significant relationship between PSV and difficulty/ease in L2 LI existed, only an extremely minute percentage of the variance of PSV was shown to be dependent on familiarity with the scenario. This means that the perceived difficulty/ease of the participants in L2 LI was the same for the more and less familiar scenarios. This finding shows that the previous acquired vocabulary knowledge of the participants affected their perception of the difficulty/ease in inferencing regardless of familiarity with the scenario.

Also, a slightly stronger relationship was found to exist between PSV and difficulty/ease in L2 LI in the less familiar scenarios compared to the more familiar ones. It can be suggested that the impact of PSV on difficulty/ease in L2 LI, however minute, might be slightly greater in the less familiar scenarios. This might be because where the participants were less familiar with the topic--that is they did not have the relevant schematic 
Topic familiarity, passage sight vocabulary, and L2 lexical inferencing

knowledge to assist them in L2 LI--PSV came into play to assist them in the LI process. Consequently this created an overall perception that inferring the target lexical item was easier. Therefore, the results obtained from this study highlight the independence of the effect of PSV and TF on the perception of ease/difficulty in LI. These results are contradictory to the results of Pulido (2007) where it was suggested that the role of passage sight vocabulary in the perception of ease/difficulty in lexical inferencing was dependent on the degree of familiarity with the topic.

An important issue could be pointed out relating to the strong independent effect of PSV found in this study with reference to the socio-educational context in Iran. In most Iranian EFL learning contexts, teaching methodology is mostly a composite of the Grammar Translation and Audiolingual methods, and a strong emphasis is put on vocabulary memorization in order to be successful in reading. This issue may result in training readers who rely heavily on their vocabulary knowledge for comprehension. Therefore, the resources and strategies that an Iranian reader chooses to use during the task of reading may be directly related to and influenced by the English classroom teaching practices in Iran. Although the results of this study do not directly provide evidence to support this theory, however, the variability observed here can propose new insights for further research into the intricate relationship between teaching pedagogy and student reading performance.

\section{Conclusion}

In sum, it can be argued that TF and PSV can directly influence the quality of processing new words. Having ample PSV and relevant background knowledge was shown to substantially ease the task of L2 LI. In the context of the Involvement Load Theory (Laufer \& Hulstijn, 2001), the interaction of these variables can influence the search and evaluation phase during the inferencing stage of a reading task whereby the reader attempts to find the meaning of unfamiliar words and assess whether the word fits into its. Therefore, the results of this study can contribute to the Involvement Load Theory for various stages of lexical development, mainly LI.

From the combined results, noteworthy pedagogical implications can be made. First, it seems very crucial that EFL/ESL teachers match the background knowledge of their students with the background knowledge presupposed by the texts which are given to them to read. As Carrell \& Eisterhold (1983) note "reading comprehension depends crucially on the reader's being able to relate information from the text to already existing background knowledge" (p.562). Therefore, familiarity with the topic in the texts should be considered before LI tasks are assigned. Based on schema theory research, activating or building appropriate background knowledge can improve the comprehension of reading texts. As Adams (1982) argues, even if students do not know all of the vocabulary in a reading passage, familiarity with the topic can reduce frustration in dealing with a new language. Pre-task instruction, content previewing, and the teaching of comprehension strategies can be suggested to encourage vocabulary development and activation of relevant background knowledge.

Second, the importance of vocabulary knowledge in reading is highlighted through the results obtained from the present study. Readers had a broad range of PSV and possessed the ability to correctly infer to some extent the meaning of the new words. Also, greater success was observed among those who had higher levels of PSV knowledge, which provides further support for Matthew Effects in language learning, as Stanovich (1986) presents for L1 learning and Ellis (1994, cited in Pulido, 2000) for L2 vocabulary acquisition. Furthermore, a greater influence of vocabulary knowledge on lexical inferencing compared to background knowledge was observed. From a pedagogical standpoint, this should come as good news, because there is not a great deal that can be done about students' life experiences and background knowledge, however teaching them vocabulary can be achieved with greater ease. Therefore, more emphasis can be put on vocabulary learning. This can be achieved by requiring EFL learners to read more authentic materials in an attempt to increase their vocabulary knowledge. This vocabulary reserve can consequently assist them in a lexical inferencing task when the time comes in an effort to reach their ultimate goal of reading comprehension. Furthermore, it is strongly recommended that EFL teachers provide systematic vocabulary instruction to assist learners in expanding, 
consolidating and elaborating their new lexicon encountered during reading (Hunt \& Beglar, 2005).

A quite noticeable implication of the findings of this research is related to evaluation. During a reading task, the learner will rely on all available resources at her disposal, namely background knowledge and vocabulary knowledge which is networkedly stored in the memory to assist in the task of LI. This network constitutes a set of interrelated conceptual features manifested in different lexical items. As such, language evaluation can be more precise if it takes into consideration these relationships. Therefore, text constructing, testing constructs, as well as assessment tools and a final evaluation, may be more finely tuned when such networking is assumed and taken into account.

Although an attempt was made to control as many variables as possible, future research may wish to consider the following suggestions if we are to further expand our knowledge of how various factors impact and interact during L2 LI. There is a possibility that other intervening factors can affect outcomes. For example, although all four narratives used in this research had extremely close readability values and were assumed to be at the same level of complexity, there might have been certain structural differences between the passages that could have contributed to different outcomes in terms of L2 LI. Future studies can examine these differences in reading texts for its potential effects on the inferencing ability of readers. Also, in an attempt to study the impact of learner differences, some factors were inevitably excluded. For example, future studies could test for the contribution of learning of meta-cognitive ability, in conjunction with PSV and TF, to better identify their role in L2 LI under various reading conditions.

Furthermore, it is important to realize that the narratives which were constructed by Pulido (2000) and adopted in this study were created based on script norming tasks of individuals who had a different native language from those that participated in this study. Therefore, it could be argued that Pulido (2000) investigated the background knowledge regarding everyday scenarios of people within the context of their native language culture. Even though everyday scenarios occur in all cultures, the order of the events involved might differ from one culture to the next. Appropriate knowledge structures which are stored in long term memory are necessary not only for comprehension to occur at the text level, but also to assist construction of meaning at the lexical level. It is expected that cultural knowledge related to everyday routines and activities influence the manner in which inferences are made for unfamiliar words. To what extent this phenomenon affected the inferencing abilities of the participants in this study is not known. Therefore, future research studies may also wish to consider cultural background knowledge when attempting to study the impact of TF on L2 LI in an effort to examine potential variability in the LI of target words during the complex task of reading.

\section{References:}

Adams, S. J. (1982). Scripts and the recognition of unfamiliar vocabulary: Enhancing second language reading skills. The Modern Language Journal, 66(2), 155-159. http://dx.doi.org/10.1111/j.1540-4781.1982.tb06975.x

Bengeleil, N. F., \& Paribakht, T. S. (2004). L2 reading proficiency and lexical inferencing by university EFL learners. The Canadian Modern Language Review, 61(2), 225-249.

Carrell , P. L. (1987). Content and formal schemata in ESL reading. TESOL Quarterly, 21(3), 461-481. http://dx.doi.org/10.2307/3586498

Carrell, P. L. (1983). Three components of background knowledge in reading comprehension. Language Learning, 33, 183-207. http://dx.doi.org/10.1111/j.1467-1770.1983.tb00534.x

Carrell, P. L., \& Eisterhold, J. C. (1983). Schema theory and ESL reading pedagogy. TESOL Quarterly, 17(4), 553-573.

Chern, C. (1993). Chinese students' word-solving strategies in reading in English. In T. Huckin, M. Haynes, \& J. Coady (Eds.), Second language reading and vocabulary learning (pp. 67-82). Norwood, NJ: Ablex.

Daneman, M., \& Green, I. (1986). Individual differences in comprehending and producing words in context. Journal of Memory and Language, 25, 1-18. http://dx.doi.org/10.1016/0749-596X(86)90018-5 
Topic familiarity, passage sight vocabulary, and L2 lexical inferencing

Davis, F. B. (1968). Research in comprehension in reading. Reading Research Quarterly, 3(4), 499-545. http://dx.doi.org/10.2307/747153

de Bot, K., Paribakht, T., \& Wesche, M. (1997). Toward a lexical processing model for the study of second language vocabulary acquisition. Studies in Second Language Acquisition, 19, 309-329. http://dx.doi.org/10.1017/S0272263197003021

Diakidoy, I. (1998). The role of reading comprehension in word meaning acquisition during reading. European Journal of Psychology of Education, 13, 131-154. http://dx.doi.org/10.1007/BF03173086

Duke, N., \& Pearson, P. D. (2002). Effective practices for developing reading comprehension. In A. Farstrup \& S. Samuels (Eds.), What research has to say about reading instruction (3rd ed.). (pp. 205-242). Newark, DE: International Reading Association.

Ellis, N. (1995). The psychology of foreign language vocabulary acquisition: Implications for CALL. CALL, 8 , 103-128. http://dx.doi.org/10.1080/0958822940080202

Freebody, P., \& Anderson, R.C. (1983). Effects of vocabulary difficulty, text cohesion, and schema availability on reading comprehension. Reading Research Quarterly, 18, 277-305. http://dx.doi.org/10.2307/747389

Grabe, W. (2004). Research on Teaching Reading. Annual Review of Applied Linguistics, 24, 44-69. http://dx.doi.org/10.1017/S0267190504000030

Graesser, A., Singer, M., \& Trabasso, T. (1994). Constructing inferences during narrative text comprehension. Psychological Review, 101, 371-395. http://dx.doi.org/10.1037/0033-295X.101.3.371

Haastrup, K. (1989). The learner as word processor. AILA Review, 6, 34-46.

Haynes, M. (1993). Patterns and perils of guessing in second language reading. In T. Huckin, M. Haynes, \& J. Coady (Eds.), Second language reading and vocabulary learning (pp. 46-64). Norwood, NJ: Ablex.

Haynes, M., \& Baker, I. (1993). American and Chinese readers learning from lexical familiarizations in English text. In T. Huckin, M. Haynes, \& J. Coady (Eds.), Second language reading and vocabulary learning (pp. 130-150). Norwood, NJ: Ablex.

Hazenberg, S., \& Hulstijn, J. H. (1996). Defining a minimal receptive second-language vocabulary for non-native university students: An empirical investigation. Applied Linguistics, 17(2), 145-163. http://dx.doi.org/10.1093/applin/17.2.145

Herman, P., Anderson, R., Pearson, P., \& Nagy, W. (1987). Incidental acquisition of word meaning from expositions with varied text features. Reading Research Quarterly, 22, 263-284. http://dx.doi.org/10.2307/747968

Hirsh, D., \& Nation, I. S. P. (1992). What vocabulary size is needed to read unsimplified texts for pleasure? Reading in a Foreign Language, 8, 689-696.

Horst, M., Cobb, T., \& Meara, P. (1998). Beyond a clockwork orange: Acquiring second language vocabulary through reading. Reading in a Foreign Language, 11, 207-223.

Hu, M., \& Nation, I. S. P. (2000). Vocabulary density and reading comprehension. Reading in a Foreign Language, 23, 403-430.

Huckin, T., \& Coady, J. (1999). Incidental vocabulary acquisition in a second language: A review. Studies in Second Language Acquisition, 21, 181-193.

Hulstijn, J. H., Hollander, M., \& Greidanus, T. (1996). Incidental vocabulary learning by advanced foreign language students: The influence of marginal glosses, dictionary use and reoccurrence of unknown words. Modern Language Journal, 80(3), 327-339. http://dx.doi.org/10.1111/j.1540-4781.1996.tb01614.x

Hunt, A. \& Beglar, D. (2005). A framework for developing EFL reading vocabulary. Reading in a Foreign language, 17(1), 23-59. Retrieved from http://www.eric.ed.gov/PDFS/EJ689121.pdf

Kintsch, W. (1988). The role of knowledge in discourse comprehension: A construction-integration model. Psychological Review, 95(2), 163-182. http://dx.doi.org/10.1037/0033-295X.95.2.163

Koda, K. (2007). Reading and language learning: Cross linguistic constraints on second language reading development. Language Learning, 57, 1-44.

Laufer B., \& Ravenhorst-Kalovski, G. C. (2010). Lexical threshold revisited: Lexical text coverage, learners' vocabulary size and reading comprehension. Reading in a Foreign Language, 22(1), 15-30. 
Atef-Vahid, S., Maftoon, P., \& Zahedi, K.

Laufer, B. (1989). What percentage of text-lexis is essential for comprehension? In C. Lauren \& M. Nordman (Eds.), Special language: From humans to thinking machines (pp. 316-323). Clevedon, England: Multilingual Matters.

Laufer, B. (1992). How much lexis is necessary for reading comprehension? In P. J. L. Arnaud \& H. B’ejoint (Eds.), Vocabulary and applied linguistics (pp. 126-132). London: Macmillan.

Laufer, B. (1997). The lexical plight in second language reading; Words you don't know, words you think you know, and words you can't guess. In J. Coady \& T. Huckin (Eds.), Second language vocabulary acquisition: A rationale for pedagogy (pp.20-33). Cambridge, England: Cambridge University Press.

Laufer, B., \& Hulstijin, J. (2001). Incidental vocabulary acquisition in a second language: The construct of task-induced involvement. Applied Linguistics, 22(1), 1-26. http://dx.doi.org/10.1093/applin/22.1.1

Lee, J. F., \& Wolf , D. (1997). A quantitative and qualitative analysis of the word-meaning inferencing strategies of L1 and L2 readers. Spanish Applied Linguistics, 1, 24-64.

Lesser, M. J. (2004). The effects of topic familiarity, mode, and pausing on second language learners' comprehension and focus on form. Studies in Second Language Acquisition, 26(1), 587-615.

Lockhart, R., \& Craik, F. (1990). Levels of processing: A retrospective commentary on a framework of memory research. Canadian Journal of Psychology, 44, 87-112. http://dx.doi.org/10.1037/h0084237

Mecartty, F. H. (2000). Lexical and grammatical knowledge in reading and listening comprehension by foreign language learners of Spanish. Applied Language Learning, 11(2), 323-348.

Nassaji, H. (2002). Schema theory and knowledge-based processes in second language reading comprehension: A need for alternative perspectives. Language Learning, 52(2), 439-481. http://dx.doi.org/10.1111/0023-8333.00189

Nassaji, H. (2003). L2 vocabulary learning from context: Strategies, knowledge sources, and their relationship with success in L2 lexical inferencing. TESOL Quarterly, 37(4), 645-670. http://dx.doi.org/10.2307/3588216

Nassaji, H. (2004). The relationship between depth of vocabulary knowledge and L2 learners' lexical inferencing strategy use and success. The Canadian Modern Language Review, 61(1), 107-134.

Nation, I. S. P. (2006). How large a vocabulary is needed for reading and listening? Canadian Modern Language Review, 63, 59-82.

Paribakht, T. S., \& Wesche, M. (1997). Vocabulary enhancement activities and reading for meaning in second language vocabulary acquisition. In J. Coady \& T. Huckin (Eds.), Second language vocabulary acquisition: A rationale for pedagogy (pp. 174-199). Cambridge: Cambridge University Press.

Paribakht, T. S., \& Wesche, M. (1999). Reading and "incidental" L2 vocabulary acquisition. An introspective study of lexical inferencing. Studies in Second Language Acquisition, 21, 195-224. http://dx.doi.org/10.1017/S027226319900203X

Parry, K. (1997). Vocabulary and comprehension: Two portraits. In J. Coady \& T. Huckin (Eds.), Second language vocabulary acquisition: A rationale for pedagogy (pp. 55-68). Cambridge: Cambridge University Press.

Pulido, D. (2000). The impact of topic familiarity, L2 reading proficiency, and L2 passage sight vocabulary on incidental vocabulary gain through reading for adult learners of Spanish as a foreign language. Unpublished Doctoral dissertation, University of Illinois at Urbana-Champaign, Michigan, U.S.A.

Pulido, D. (2003). Modeling the role of second language proficiency and topic familiarity in second language incidental vocabulary acquisition through reading. Language Learning, 53(2), 233-284.

http://dx.doi.org/10.1111/1467-9922.00217

Pulido, D. (2004). The effect of cultural familiarity on incidental vocabulary acquisition through reading. The Reading Matrix, 4(2), 20-53.

Pulido, D. (2007). The effects of topic familiarity and passage sight vocabulary on L2 lexical inferencing and retention through reading. Applied Linguistics, 28(1), 68-86. http://dx.doi.org/10.1093/applin/aml049

Pulido, D., \& Hambrick, D. Z. (2008). The virtuous circle: Modeling individual differences in L2 reading and vocabulary. Reading in a Foreign Language, 20, 164-190.

Schmitt, N., Jiang, X., \& Grabe, W. (2011). The percentage of words known in a text and reading comprehension. 
The Modern Language Journal, 95, 26-43. http://dx.doi.org/10.1111/j.1540-4781.2011.01146.x

Spilich, G.J., Vesonder, G.T., Chiesi, H.L., \& Voss, J.F. (1979). Text processing of domain-related information for individuals with high and low domain knowledge. Journal of Verbal Learning and Verbal Behavior, 18, 275-290. http://dx.doi.org/10.1016/S0022-5371(79)90155-5

Stahl, S. A., \& Fairbanks, M. M. (1986). The effects of vocabulary instruction: A model-based meta-analysis. Review of Educational Research, 56(1), 72-110.

Stahl, S. A., Jacobson, M. J., Davis, C. E., \& Davis, R. L. (1989). Prior knowledge and difficult vocabulary in the comprehension of unfamiliar texts. Reading Research Quarterly, 24(1), 27-43. http://dx.doi.org/10.2307/748009

Stanovich, K. E. (1986). Matthew effects in reading: Some consequences of individual differences in the acquisition of literacy. Reading Research Quarterly, 21(4), 360-407. http://dx.doi.org/10.1598/RRQ.21.4.1

vanDaalen-Kapteijns, M., \& Elshout-Mohr, M. (1981). The acquisition of word meanings as a cognitive learning process. Journal of Verbal Learning and Verbal Behavior, 20, 386-399. http://dx.doi.org/10.1016/S0022-5371(81)90515-6 


\section{L2 Lexical Inferencing Measure}

Passage 1: Carefully read the passage at least two times at your own pace. Begin with the title and continue to the end. Please make sure that you have understood the passage well enough to be able to guess the meaning of each underlined-bold-faced word.

\section{The Doctor's Appointment}

It was January and Jack felt sick. He thought that he had the flu because it was just the season to have it. So he went to the clinic. He entered into the rosking room of Doctor Smith and went over to the receptionist to $\underline{\text { flim }}$ in. Afterward, he sat down and crimmed through some magazines. He also looked around at the other patients. Soon after the nurse called him, Jack followed her to the exam mant. There, the nurse took his vital blims. Shortly afterward, the doctor came in and asked him how he felt. Jack was very congested and had chills and a headache. Then, he got up on the exam table and while he opened his mouth the doctor fraiged his throat. Then Jack got dressed. Later, the doctor wrote down something in his medical file and he gave Jack a braiment. He explained to him that the syrup was for his firt. He also gave him some advice. Then, Jack went directly to the pharmacy of the clinic to buy his medicine. Finally, Jack left the clinic.

TASK ONE: Clearly print the Farsi TRANSLATION of each of the bold-faced underlined words in the passage above in the space provided below. You can provide an exact or approximate translation, or describe what you think the word means.

\section{$1-\underline{\text { rosking }}=$}

2- flim $=$

\section{3- crimmed $=$}

4- $\underline{\text { mant }}=$

5- $\underline{\text { blims }}=$

6 - fraiged $=$

7 - braiment $=$

\section{8- $\underline{\text { firt }}=$}


TASK TWO: Immediately after you have guessed the translation of each bold-face underlined word; specify the degree of ease or difficulty in guessing the translation of the word using a scale of 1-6 provided below.

\begin{tabular}{|c|c|c|c|c|c|c|c|}
\hline $\begin{array}{l}\text { Very Easy } \\
\text { (6) }\end{array}$ & $\begin{array}{c}\text { Easy } \\
(5)\end{array}$ & $\begin{array}{l}\text { Moderately } \\
\text { easy } \\
\text { (4) }\end{array}$ & $\begin{array}{l}\text { Moderately } \\
\text { difficult } \\
\text { (3) }\end{array}$ & $\begin{array}{l}\text { Difficult } \\
\text { (2) }\end{array}$ & $\begin{array}{l}\text { Very difficult } \\
\text { (1) }\end{array}$ & $\begin{array}{l}\text { Bold-faced } \\
\text { underlined } \\
\text { words }\end{array}$ & \\
\hline & & & & & & rosking & 1 \\
\hline & & & & & & flim & 2 \\
\hline & & & & & & crimmed & 3 \\
\hline & & & & & & $\underline{\text { mant }}$ & 4 \\
\hline & & & & & & $\underline{\text { blims }}$ & 5 \\
\hline & & & & & & fraiged & 6 \\
\hline & & & & & & braiment & 7 \\
\hline & & & & & & firt & 8 \\
\hline
\end{tabular}


Passage 2: Carefully read the passage at least two times at your own pace. Begin with the title and continue to the end. Please make sure that you have understood the passage well enough to be able to guess the meaning of each underlined-bold-faced word.

\section{Buying a Home}

Mark wanted to buy a home. So he obtained a prestal to see what there was on the market. He began to investigate little by little the neighborhoods of his city. He wanted a house with a lot of space. He also wanted a lot of windows. So, when he knew what he wanted he went to the real-estate tanbury to get more informed. Several days later, Mark and the prailor visited various houses throughout the city. In each one of them Mark informed himself of the potential problems. After looking around for a week, he finally found a house that he liked. Then he had to austify the sale with the owner. Afterward, Mark and his lawyer arranged escrow. He had to put down a brumfil for the house. Then he went to the bank to arrange the traist. There, he decided how much he wanted to spend on the plocker. Before closing the proctal, he inspected the house for the last time. Since everything seemed alright to him, he signed all of the necessary paperwork. Instantly, he became a homeowner.

TASK ONE: Clearly print the Farsi TRANSLATION of each of the bold-faced underlined words in the passage above in the space provided below. You can provide an exact or approximate translation, or describe what you think the word means.

\section{$1-$ prestal $=$ \\ $2-\underline{\text { tanbury }}=$ \\ 3- prailor $=$ \\ 4- $\underline{\text { austify }}=$ \\ 5 - $\underline{\text { brumfil }}=$ \\ 6- $\underline{\text { traist }}=$ \\ 7- plocker $=$ \\ $8-$ proctal $=$}


TASK TWO: Immediately after you have guessed the translation of each bold-face underlined word; specify the degree of ease or difficulty in guessing the translation of the word using a scale of 1-6 provided below.

\begin{tabular}{|c|c|c|c|c|c|c|c|}
\hline $\begin{array}{l}\text { Very Easy } \\
\text { (6) }\end{array}$ & $\begin{array}{c}\text { Easy } \\
(5)\end{array}$ & $\begin{array}{l}\text { Moderately } \\
\text { easy } \\
\text { (4) }\end{array}$ & $\begin{array}{l}\text { Moderately } \\
\text { difficult } \\
\text { (3) }\end{array}$ & $\begin{array}{l}\text { Difficult } \\
\text { (2) }\end{array}$ & $\begin{array}{l}\text { Very difficult } \\
\text { (1) }\end{array}$ & $\begin{array}{l}\text { Bold-faced } \\
\text { underlined } \\
\text { words }\end{array}$ & \\
\hline & & & & & & prestal & 1 \\
\hline & & & & & & tanbury & 2 \\
\hline & & & & & & prailor & 3 \\
\hline & & & & & & ustify & 4 \\
\hline & & & & & & $\underline{\text { brumfil }}$ & 5 \\
\hline & & & & & & $\underline{\text { traist }}$ & 6 \\
\hline & & & & & & plocker & 7 \\
\hline & & & & & & proctal & 8 \\
\hline
\end{tabular}


Passage 3: Carefully read the passage at least two times at your own pace. Begin with the title and continue to the end. Please make sure that you have understood the passage well enough to be able to guess the meaning of each underlined-bold-faced word.

The Trip to the Supermarket

Today Sue realized that there was nothing in the refrigerator, so she got her purse and drove to the supermarket. She parked the car and entered into the supermarket. First, she got a $\underline{\text { shinsk }}$ and took the list out of her purse. She began to take a trip through the fresks. First, she went to the canned goods section because she wanted soup. There were so many brands that she decided to prizlate the prices. Then, she continued on toward the fruit and vegetable stands to buy grapes. There, she chose a bunch. Afterwards, she went to the bakery to buy bread. She greeted the shopkeeper and asked for a loaf. Then she continued on through the supermarket to see if she needed anything else. She had everything, so she walked toward the brumpet. There were many people standing in line, so Sue began to read the mostings. Finally, it was her turn, so she placed everything on the bintup and the clerk began to dask the prices. Afterward, Sue took out her credit card and paid her bill. Finally, she got the rizlet bags and left the supermarket.

TASK ONE: Clearly print the Farsi TRANSLATION of each of the bold-faced underlined words in the passage above in the space provided below. You can provide an exact or approximate translation, or describe what you think the word means.

\section{$1-\underline{\text { shinsk }}=$ \\ 2- $\underline{\text { fresks }}=$ \\ 3 - prizlate $=$ \\ 4- brumpet $=$ \\ 5- $\underline{\text { mostings }}=$ \\ 6- bintup $=$ \\ $7-\underline{\text { dask }}=$ \\ 8 - $\underline{\text { rizlet }}=$}


TASK TWO: Immediately after you have guessed the translation of each bold-face underlined word, specify the degree of ease or difficulty in guessing the translation of the word using a scale of 1-6 provided below.

\begin{tabular}{|c|c|c|c|c|c|c|c|}
\hline $\begin{array}{l}\text { Very Easy } \\
\text { (6) }\end{array}$ & $\begin{array}{c}\text { Easy } \\
(5)\end{array}$ & $\begin{array}{l}\text { Moderately } \\
\text { easy } \\
\text { (4) }\end{array}$ & $\begin{array}{l}\text { Moderately } \\
\text { difficult } \\
\text { (3) }\end{array}$ & $\begin{array}{l}\text { Difficult } \\
\text { (2) }\end{array}$ & $\begin{array}{l}\text { Very difficult } \\
\text { (1) }\end{array}$ & $\begin{array}{l}\text { Bold-faced } \\
\text { underlined } \\
\text { words }\end{array}$ & \\
\hline & & & & & & shinsk & 1 \\
\hline & & & & & & fresks & 2 \\
\hline & & & & & & prizlate & 3 \\
\hline & & & & & & brumpet & 4 \\
\hline & & & & & & $\underline{\text { mostings }}$ & 5 \\
\hline & & & & & & $\underline{\text { bintup }}$ & 6 \\
\hline & & & & & & $\underline{\text { dask }}$ & 7 \\
\hline & & & & & & rizlet & 8 \\
\hline
\end{tabular}


Atef-Vahid, S., Maftoon, P., \& Zahedi, K. 